\title{
Hubungan Pengetahuan Perawat Tentang Hais (Healthcare Associated Infections) dengan Kepatuhan Hand Hygiene di Ruang Rawat Inap RSUD Encik Mariyam Tahun 2020 \\ Sarah
}

Program Studi Ilmu Keperawatan Sekolah Tinggi Ilmu Kesehatan Awal Bros Batam Email korespondensi: bundaraja81@gmail.com

\begin{abstract}
ABSTRAK
Hand hygiene merupakan teknik dasar yang penting dalam pencegahan HAIs namun tingkat kepatuhan perawat dalam melakukan hand hygiene masih rendah. Tujuan penelitian ini adalah mengetahui hubungan pengetahuan perawat tentang HAIs dengan kepatuhan hand hygiene di ruang rawat inap RSUD Encik Mariyam tahun 2020. Penelitian ini menggunakan desain deskriptif korelasional dan pendekatan cross-sectional. Metode sampling yang digunakan adalah total sampling dengan besar sample 32 orang perawat di ruang rawat inap RSUD Encik Mariyam. Data penelitian dikumpulkan melalui metode observasi oleh peneliti dan pengisian kuesioner oleh responden. Data hasil penelitian dianalisa dengan uji Somers' D. Hasil analisa univariat didapatkan gambaran pengetahuan perawat tentang HAIs pada kategori sedang (53.1\%) dan gambaran kepatuhan hand hygiene pada kategori dilakukan dengan baik (71.9\%). Hasil analisa bivariate didapatkan $p$ value= 0.007 sehingga dapat disimpulkan ada hubungan yang signifikan antara pengetahuan perawat tentang HAIs dengan kepatuhan hand hygiene di ruang rawat inap RSUD Encik Mariyam tahun 2020. Berdasarkan hasil penelitian ini diharapkan agar meningkatkan pengetahuan perawat tentang HAIs dan manajemennya melalui seminar / sosialisasi dan pelatihan guna meningkatkan kesadaran perawat akan pentingnya pencegahan HAIs dengan hal-hal sederhana seperti hand hygiene.
\end{abstract}

Kata kunci: HAIs; kepatuhan; hand hygiene

\section{The Relationship Between Nurse Knowledge About Hais (Healthcare Associated Infections) and Hand Hygiene Compliance in Encik Mariyam Hospital Year 2020}

\begin{abstract}
It is known that hand hygiene is an important basic technique in preventing HAIs, yet the level of compliance nurses in performing correct and regular hand hygiene is still low. The purpose of research is to determine the relationship between nurses knowledge about HAIs and hand hygiene compliance at Encik Mariam Hospital year 2020. This is an observational research, with a descriptive correlational design and cross-sectional as its data collecting approach. 32 inpatient nurses are chosen as samples by total sampling method. The research data then analyzed by using the Somers' D test using the SPSS. The frequency table shown an overview of a moderate nurses knowledge about HAIs $(53.1 \%)$ and an overview of adequate compliance of hand hygiene $(71.9 \%)$. The bivariate analysis obtained $p$ value $=0.007$ in which it could be concluded there is a significant relationship between nurses knowledge about HAIs and hand hygiene compliance in Encik Mariyam Hospital year 2020. Based on the research results it is expected of management to increase the nurses knowledge about HAIs and its management through seminars and training in order to increase the awareness of the importance of HAIs prevention.
\end{abstract}

Keywords: HAIs; Compliance; Handhygiene 


\section{PENDAHULUAN}

Word Health Organization (WHO) mendefinisikan "Healthcare associated infections (HAIs) juga disebut dengan infeksi nosokomial, sebagai infeksi yang terjadi pada pasien selama proses perawatan di rumah sakit atau fasilitas kesehatan lainnya yang tidak ditemukan atau di derita pada saat masuk (Tan, 2015). Klien dalam lingkungan fasilitas layanan kesehatan beresiko terkena infeksi karena daya tahan yang menurun terhadap mikroorganisme infeksius, meningkatnya paparan terhadap jumlah dan jenis penyakit yang disebabkan oleh mikroorganisme dan prosedur invasif (Herman, 2016). HAIs dikaitkan dengan peningkatan morbiditas, mortalitas, lama tinggal di rumah sakit, peningkatan biaya perawatan kesehatan, dan resistensi antibiotik di fasilitas perawatan akut dan jangka panjang.

\section{Healthcare associated infections}

(HAIs) bisa bersumber dari petugas kesehatan, pasien yang lain, alat dan bahan yang digunakan untuk pengobatan maupun dari lingkungan rumah sakit (Adhiwijaya, 2017). Walaupun penyebaran penyakit infeksi dirumah sakit telah dikenal sejak lama, pemahaman bagaimana mencegah HAIs (Heathcare associated infections) dan implementasi secara baik masih sulit (Ningsih, 2017). Sementara dengan mempraktikkan teknik pencegahan dan pengendalian infeksi yang baik dan benar, perawat dapat menghindarkan penyebaran mikroorganisme terhadap klien (Herman, 2016).

Hand hygiene adalah istilah yang digunakan untuk mencuci tangan menggunakan antiseptik pencuci tangan. Meskipun hand hygiene merupakan teknik dasar yang penting dalam pencegahan infeksi namun tingkat kepatuhan petugas kesehatan khususnya perawat dalam melakukan hand hygiene masih rendah. Tingkat kepatuhan perawat dalam melakukan cuci tangan di Amerika Serikat masih sekitar 50\%, di Australia masih sekitar 65\%. Sama halnya dengan di Rumah Sakit Cipto Mangunkusumo (RSCM) kepatuhan perawat dalam melakukan cuci tangan hanya sekitar $60 \%$ (Utami, 2017). Hasil penelitian perilaku kewaspadaan standar di RSUD Tanjung Uban Kepulauan Riau menunjukkan hasil kepatuhan mencuci tangan sebesar $54.7 \%$ (Yulita, 2016).

Hand hygiene merupakan landasan pencegahan infeksi dan tindakan pengendalian untuk mengurangi HAIs, namun meskipun banyak pedoman cuci tangan telah diterbitkan, kepatuhan petugas dalam melakukan cuci tangan tetap menjadi tantangan. Faktor penyebab rendahnya angka kepatuhan tersebut adalah rendahnya pengetahuan tentang penularan HAIs, dan kesadaran pentingnya melakukan cuci tangan. Dari hasil penelitian tersebut disimpulkan pendidikan yang berkelanjutan tentang HAIs dan pencegahannya perlu dilakukan (Sulistyowati, 2016). Penelitian lain menyebutkan beberapa faktor terkait rendahnya angka kepatuhan hand hygiene ini adalah kurangnya pengetahuan akan bahaya HAIs dan beban kerja yang tinggi sehingga perawat merasa tidak sempat untuk selalu mencuci tangan. Sosialisasi HAIs perlu dilakukan secara berkelanjutan untuk meningkatkan kewaspadaan dan kesadaran pentingnya pencegahan HAIs (Sheth, 2015).

Berdasarkan studi rekam medis yang dilakukan oleh peneliti di RSUD Encik Mariyam diketahui angka prevalensi HAIs yaitu 3,09\%. Angka tersebut berada diatas standar yang telah ditetapkan oleh Depkes RI yaitu $\leq 1,5 \%$. Dengan prevalensi tertinggi pada infeksi daerah operasi (IDO), dan infeksi aliran darah perifer (IADP). Hasil wawancara dengan komite PPI diketahui kepatuhan petugas kesehatan dalam melaksanakan hand hygiene pada bulan Jan-Sep 2019 adalah (61,7\%), 
dimana nilai tersebut mengalami penurunan dibanding tahun sebelumnya. Data surveillance PPI RSUD Encik Maryam tentang kepatuhan hand hygiene perawat tahun 2016 (57,6\%), 2017 (54,7), dan 2018 $(66,1 \%)$. Hasil wawancara dengan 10 orang perawat di instalasi rawat inap didapatkan data pengetahuan tentang HAIs yang masih rendah (40\%), sementara perawat tidak melakukan hand hygiene karena tangan tidak tampak kotor, pasien tidak menderita penyakit infeksius, dan tidak sempat karena banyaknya pekerjaan. Diketahui perawat mendapat inhouse training pencegahan dan pengendalian infeksi ketika pertama kali masuk dan tidak mendapatkan pelatihan ulang lagi (Komite PPI RSUD Encik Mariyam, 2019).

\section{METODE PENELITIAN}

Rancang penelitian observasional ini menggunakan desain deskriptif korelasional dan pendekatan crosssectional. Tekhnik sampling yang digunakan adalah total sampling dengan besar sampel yang digunakan sebanyak 32 responden yang merupakan perawat di RSUD Encik Maryam. Pengumpulan data dilakukan dengan pengisian kuesioner. Hasil penelitian dianalisa dengan uji Spearman rho dengan nilai kemaknaan $0.05 \%$.

\section{HASIL DAN PEMBAHASAN}

\section{Analisa Univariat}

Tabel 1

Distribusi frekuensi karakteristik responden, pengetahuan tentang HAIs dan tingkat kepatuhan handhygiene $(\mathrm{n}=32)$

\begin{tabular}{|c|c|c|c|}
\hline No & Karakteristik & $\mathrm{f}$ & $\%$ \\
\hline \multirow[t]{3}{*}{1} & Jenis kelamin & & \\
\hline & Laki-laki & 9 & 28.1 \\
\hline & Perempuan & 23 & 71.9 \\
\hline \multirow[t]{4}{*}{2} & Umur & & \\
\hline & $<25$ tahun & 2 & 9.4 \\
\hline & 26-35 tahun & 19 & 59.4 \\
\hline & 36-45 tahun & 10 & 31.2 \\
\hline \multirow[t]{5}{*}{3} & Pendidikan & & \\
\hline & DIII Kep/ Keb & 21 & 65.6 \\
\hline & DIV Kep/ Keb & 4 & 12.5 \\
\hline & S1 Kep & 5 & 15.6 \\
\hline & Ners & 2 & 6.3 \\
\hline \multirow[t]{5}{*}{4} & Masa kerja & & \\
\hline & $<1$ tahun & 3 & 9.4 \\
\hline & $1-5$ tahun & 13 & 40.6 \\
\hline & 6-10 tahun & 12 & 37.5 \\
\hline & $>10$ tahun & 4 & 12.5 \\
\hline \multirow[t]{4}{*}{5} & Tingkat Pengetahuan & & \\
\hline & Rendah & 6 & 18.8 \\
\hline & Sedang & 15 & 53.1 \\
\hline & Tinggi & 11 & 28.1 \\
\hline 6 & Kepatuhan hand hygiene & & \\
\hline
\end{tabular}




$\begin{array}{lcc}\text { Tidak dilakukan dengan baik } & 9 & 28.1 \\ \text { Dilakukan dengan baik } & 23 & 71.9\end{array}$

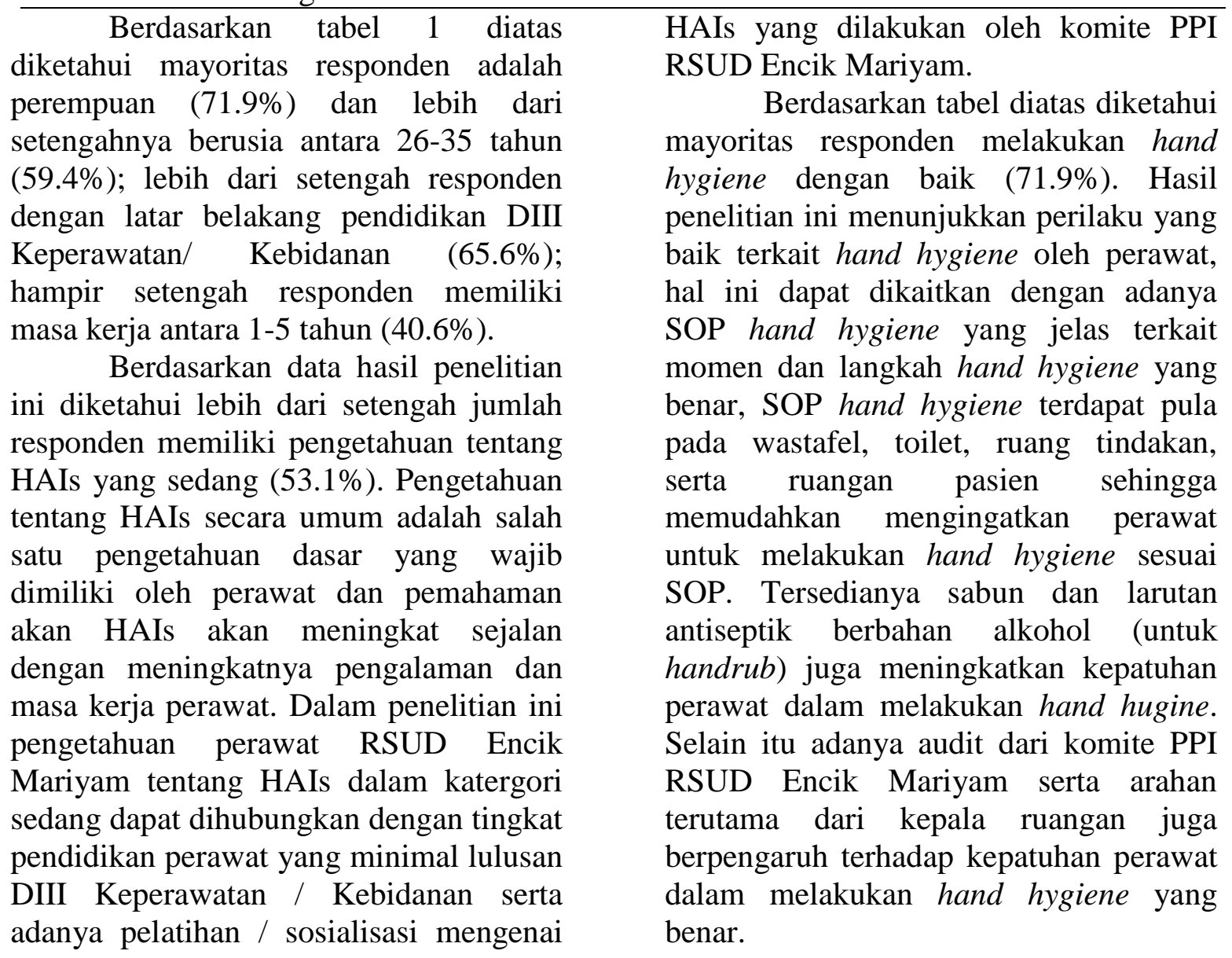

2. Hubungan pengetahuan tentang HAIs dengan kepatuhan handhygiene

Tabel 2

Hubungan pengetahuan perawat tentang HAIs (healthcare associated infections) dengan kepatuhan hand hygiene di ruang rawat inap RSUD Encik Mariyam tahun 2020

\begin{tabular}{lcc}
\hline Variabel & Value & \multicolumn{2}{c}{ Sig. } \\
\hline Symmetric & .450 & .007 \\
Pengetahuan HAIs Dependent & .560 & .007 \\
Kepatuhan Hand hygiene Dependent & .375 & .007 \\
\hline
\end{tabular}

Berdasarkan hasil penelitian pada tabel 4.4 dapat diketahui hasil analisis hubungan pengetahuan perawat tentang HAIs dengan kepatuhan hand hygiene dengan nilai signifikan sebesar 0.007 (p value $=0.007)$ dimana pada taraf signifikansi $5 \%, \quad \mathrm{p}<0.05$ dapat disimpulkan $\mathrm{Ha}$ (hipotesis alternatif) diterima yang berarti ada hubungan pengetahuan perawat tentang HAIs 
dengan kepatuhan hand hygiene di ruang rawat inap RSUD Encik Mariyam. Nilai value symmetric $\mathrm{d}=0.450$ bermakna korelasi sedang pada hubungan timbal balik antara pengetahuan HAIs dan kepatuhan hand hygiene; korelasi sedang pada hubungan pengetahuan HAIs dan kepatuhan hand hygiene $(\mathrm{d}=0.560)$; dan korelasi lemah pada hubungan kepatuhan hand hygiene dengan pengetahuan HAIs.

Salah satu faktor yang turut mempengaruhi kepatuhan perawat dalam melaksanakan hand hygiene antara lain ada kurangnya pengetahuan tentang healthcare associated infestions (HAIs) yang penyebarannya terutama dari kontak petugas kesehatan ke pasien dan sebaliknya, dimana hand hygiene merupakan salh satu metode yang efektif dalam mencegah penularan HAIs tersebut. Selain itu faktor jumlah pasien dalam waktu yang bersamaan dan aktivitas yang banyak merupakan faktor yang mempengaruhi rendahnya tingkat kepatuhan perawat dalam pelaksanaan hand hygiene. Motivasi perawat untuk patuh dalam melaksanakan hand hygiene ketika berada dalam ruangan juga masih kurang terutama untuk tindakan yang beresiko rendah, meskipun untuk sarana palaksanaan hand hygiene sudah tersedia di setiap ruangan dan mudah di akses.

Dengan demikian salah satu hal yang sangat penting untuk seluruh petugas pelayanan kesehatan yaitu agar mempelajari secara tepat prosedur dan pelaksanaan hand hygiene. Program edukasi perlu dilakukan untuk memberikan penjelasan pentingnya pelaksanaan hand hygiene dan memberikan panduan yang jelas pada situasi apa hand hygiene harus dilakukan. Hal ini karena pengetahuan atau aspek kognitif merupakan domain yang sangat penting dalam membentuk tindakan seseorang (overt behavior), dimana tindakan yang didasarkan atas pengetahuan akan lebih bertahan lama dibandingkan tindakan yang tidak didasarkan atas pengetahuan. Dalam penyempurnaan pelaksanaan hand hygiene suatu pendekatan multimodalitas harus dilakukan untuk meningkatkan kepatuhan yaitu kebiasaan dari setiap individu, suasana dari institusi, penanganan kendala yang terdapat dilingkungan, penggunaan poster untuk mempromosikan hand hygiene, dan manejemen pendukung yang kuat dari program rumah sakit.

Dalam meningkatkan kepatuhan pelaksanaan hand hygiene, beberapa hal yang perlu di ketahui yaitu pengetahuan, kebiasaan setiap individu, dan fasilitas untuk melaksanakan hand hgyiene. Dari beberapa faktor tersebut, maka jika dihubungkan dengan kondisi lingkungan dan fasilitas di RSUD Encik Mariyam pada saat observasi dilakukan peneliti terkait pelaksanaan hand washing yang dilakukan oleh perawat dapat ditemukan fasilitas untuk melaksanakan hand hygiene sudah adekuat, yakni dilihat dari adanya cairan antiseptik berbahan alkohol yang berada di nurse station dan di sisi pintu ruang rawat inap dan di masingmasing tempat tidur pasien; terdapat pula wastafel beserta handsoap dan tisu kering. Hal tersebut dari sisi sarana sudah mendukung untuk pelaksanaan hand hygiene yang optimal di lingkungan rumah sakit.

Penelitian terkait dengan judul hubungan pengetahuan dengan kepatuhan perawat dalam pelaksanaan hand hygiene di ruang rawat inap RSU PKU Muhammadiyah Bantul oleh Sari (2019) didapatkan hasil adanya hubungan yang bermakna signifikan antara kedua variabel dengan $p$ value $=0.040$. Penelitian sejenis lainnya oleh Sunarni (2019) mendapatkan hasil uji statistik dengan menggunakan uji Spearman rank nilai $p$ value $0,000<0,05$ yang bermakna ada hubungan pengetahuan perawat dengan perilaku kepatuhan five moment for hand hygiene di RSUD dr. Soehadi Prijonegoro Sragen.

Hasil observasi di ruangan rawat inap RSUD Encik Mariyam didapatkan 
kepatuhan responden dalam melakukan hand hygiene sudah baik, tetapi untuk pelaksanaan hand hygiene sesuai five moment hand hygiene yang harus dilaksanakan mengacu pada WHO seperti sebelum kontak dengan pasien, setelah kontak dengan pasien, sebelum melakukan tindakan aseptic, setelah terpapar cairan tubuh pasien dan setelah kontak dengan lingkungan masih

\section{SIMPULAN}

1. Lebih dari setengah jumlah responden memiliki pengetahuan tentang HAIs pada kategori sedang.

2. Mayoritas responden melakukan handhygiene dengan baik.

3. Ada hubungan yang signifikan antara pengetahuan perawat tentang HAIs dengan kepatuhan hand hygiene di RSUD Encik Mariyam.

\section{UCAPAN TERIMAKASIH}

1. Bapak Prof. Dr. Fadil Oenzil, PhD. Sp.GK selaku Ketua Stikes Awal bros Batam;

2. Ibu Ns. Sri Muharni, S.Kep., M.Kep selaku Ka. Prodi Sarjana Keperawatan Stikes Awal bros Batam dan Pembimbing I;

3. Ibu Utari Christya Wardhani, Ners,M.Kep selaku pembimbing II;

4. Bapak dr. Suryadi selaku direktur RSUD Encik Mariyam

5. Seluruh Dosen dan staf Pengajar yang sudah mendukung proses penyusunan skripsi ini dari awal hingg akhir.

6. Seluruh Mahasiswa Sarjana Keperawatan Angkatan XI Stikes Awalbros

\section{DAFTAR PUSTAKA}

Adhiwijaya, A. 2017. Eksplorasi Kendala Tim PPI dalam Pelaksanaan Pencegahan dan Pengendalian Infeksi di RSUD Labuang Baji

\begin{abstract}
didapatkan kelalaian. Pada saat dilakukannya observasi seluruh responden lebih banyak melakukan prosedure alternative yaitu handrub dengan cairan antiseptic berbahan alkohol, dan sebagian responden dalam melakukan prosedur handrub masih kurang dari waktu yang direkomendasikan yaitu berkisar 20-30 detik.
\end{abstract}

Makassar. Jurnal Ilmiah Kesehatan Diagnosis 11(4):371-376.

Cahyo, F. 2018. Makalah Infeksi Nosokomial. [online] https://www.scr ibd.com/document/389152845/Makal ah-Nosokomial-Fdc. Diakses pada 20 Nop 2019.

Damanik, H. 2018. Hubungan Pengetahuan Perawat Tentang Infeksi Nosokomial Dengan Tindakan Pencegahannya Pada Pasien Pascabedah Di Ruang Rawat Inap Rumah Sakit Imelda Medan. Jurnal Ilmiah Keperawatan IMELDAVol. 4, No. 1, Februari 2018.

Darmadi, 2018. Infeksi Nosokomial: Problematika dan Pengendaliannya. Jakarta: Salemba Medika.

Djojosugito, A. 2014. Buku Manual Pengendalian Infeksi Nosokomial di Rumah Sakit. Jakarta

Hapsari, A. 2018. Pengetahuan Petugas Surveilans Tentang Identifikasi Healthcare-Associated Infections Di Surabaya. Jurnal Berkala Epidemiologi, 6 (2)2018, 130-138.

Herman, M. 2016. Sarana dan Prasarana Rumah Sakit Pemerintah dalam Upaya Pencegahan dan Pengendalian Infeksi di Indonesia. 
Jurnal Kefarmasin Indonesia 6(2):137-146.

Karaslaan, A et al. 2014. Compliance of Healthcare Workers with Hand Hygiene Practices in Neonatal and Pediatric Intensive Care Units: Overt Observation. Interdiscip Perspect Infect Dis. 2014;2014:306478.

Masloman, A. 2015. Analisis Pelaksanaan Pencegahan dan Pengendalian Infeksi di Ruang Operasi RSUD Dr Sam Ratulangi Tondano. JIKMU 5(2):238-249.

Ningsih, D. 2017. Patient Safety Project Pengurangan Resiko Infeksi Melalui Penerapan PPI. Surakarta: RSKU.

Notoatmodjo, S. 2014. Ilmu Perilaku Kesehatan. Jakarta: Rineka Cipta.

Peraturan Menteri Kesehatan RI No 27 tahun 2017 tentang Pedoman Pencegahan dan Pengendalian Infeksi di Fasilitas Pelayanan Kesehatan. http://ditjenpp.kemenkumham.go.id/a rsip/bn/2017/bn857-2017.pdf

Diakses pada 20 Nopember 2019.

Ratnawati, L \& Sianturi, S. (2018). Faktor Faktor Yang Berhubungan Dengan Kepatuhan Perawat Dalam Menerapkan Hand Hygiene. Jurnal Ilmu Keperawatan dan Kebidanan. 9. 148. 10.26751/jikk.v9i2.458.

Rikayanti, K. 2014. Hubungan Tingkat Pengetahuan Dengan Perilaku Mencuci Tangan Petugas Kesehatan di Rumah Sakit Umum Daerah Badung Tahun 2013. Community Health. [Online] 2:1.

Sari, T. Hastuti, S. 2019. Faktor-Faktor Yang Berhubungan Dengan Kepatuhan Perawat Dalam Pelaksanaan Hand Hygiene di Ruang Rawat Inap RSU PKU Muhammadiyah Bantul. [online ] http://eprints.uad.ac.id/14960/3/T1 1500029278 NASKAH\%20PUBLIK
ASI.pdf. Diakses pada 20 Februari 2020.

Septiari, B. 2016. Infeksi Nosokomial. Jakarta: Nuha Medica

Sheth, A et al. 2015. Assessing the awareness and practice of Hospital Acquired Infections (HAIs) among nursing staff of Civil Hospital, Rajkot, Gujarat, India. International Journal of Research in Medical Science.

Soedarto. 2016. Infeksi Nosokomial di Rumah Sakit. 1st ed. Jakarta: Sagung Seto.

Sulistyowati, D. 2016. Hubungan Tingkat Pengetahuan dan Sikap Perawat tentang Infeksi Nosokomial (Inos) dengan Perilaku Pencegahan Inos di Ruang Bedah RSUD Dr. Moewardi Surakarta. Jurnal Keperawatan Global, Volume 1, No1, Juni 2016 hlm 01-54.

Sunarni. dkk. 2019. Pengetahuan perawat dengan perilaku kepatuhan five moment for hand hygiene. INPRESS JURNAL LITBANG SUKOWATI volume 4 nomor 1 november 2019 hal $1-10$

Tan, A et al. 2015. Assessing Healthcare Associated Infections and Hand Hygiene Perceptions amongst Healthcare Professionals. International Journal of Caring Sciences January-April 2015 Volume 8 Issue 1.

Utami, R. 2017. Tingkat Kepatuhan Perawat Melakukan Hand Hygienedi IGD RSUD dr. R. Goeteng Taroenadibrata Purbalingga. [online] http://repository .ump.ac.id/4421/2/Rizka\%20Dwi\%20 Utami\%20BAB\%20I.pdf. Diakses pada 20 Nopember 2019.

WHO. 2016. Health care-associated infections fact sheet. [online] https://www.who.int/gpsc/country_w 
ork/gpsc_ccisc_fact_sheet_en.pdf. Diakses pada 20 Nopember 2019

Yulita, Y. 2016. Pengaruh Supervisi Refektif Interaktif terhadapPerilaku Keselamatan Perawat pada Bahaya Agen Biologik Di RSUD Provinsi Kepulauan Riau Tanjung Uban. Skripsi tidak diterbitkan.
Zulpahiyana. 2014. Efektivitas Simulasi Hand hygiene pada Handover Keperawatan dalam Meningkatkan Kepatuhan Hand hygiene Perawat. Program Pacasarjana Manajemen Rumah Sakit Universitas Muhammadiyah Yogyakarta, Yogyakarta. 